TITLE:

\title{
A Case Study of Observational Method for a Failed Geotechnical Excavation in Singapore
}

$\operatorname{AUTHOR}(S)$ :

Iwasaki, Yoshinori

\section{CITATION:}

Iwasaki, Yoshinori. A Case Study of Observational Method for a Failed Geotechnical Excavation in Singapore. Proceeding of TC302 Symposium Osaka 2011 : International Symposium on Backwards Problem in Geotechnical Engineering and Monitoring of Geo ..

ISSUE DATE:

2011

URL:

http://hdl.handle.net/2433/173829

RIGHT: 


\section{A Case Study of Observational Method for a Failed Geotechnical Excavation in Singapore}

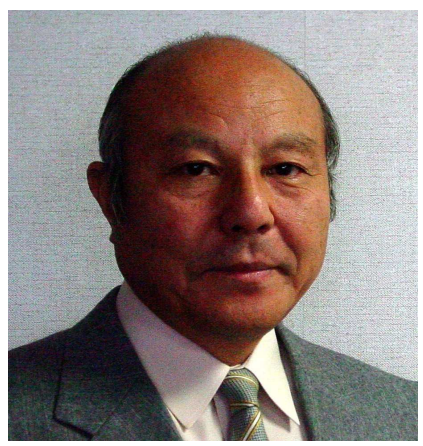

Y. Iwasaki

Executive Director, Geo-Research Institute, Osaka, <yoshi-iw@geor.or.jp>

ABSTRACT: Observational Method (OM) was studied based upon a case history of failed geotechnical excavation in Singapore. Several items including inclinometer provide vital information on the safety of the geotechnical construction sites. Engineer who is specialized in OM, adequate knowledge of geotechnical engineering as well as instrumentation, should be engaged during the design and construction phase. An ISO standardization is necessary to provide a basic process to implement $\mathrm{OM}$.

\section{INTRODUCTON}

Observational Method was proposed by Terzaghi and Peck (1967) for several reasons including to confirm the assumed geotechnical condition during design stage as well as to avoid critical situation in geotechnical construction.
One of the failed cases in Singapore that has been described by Prof.Ishihara (2011) during the TC302 Osaka Symposium is discussed in term of Observational Method.

After the collapse of Nicoll Highway on 20 April 2004, a Committee of Inquiry was established (COI) to study the process of failure.

Fig.1 General Plan view

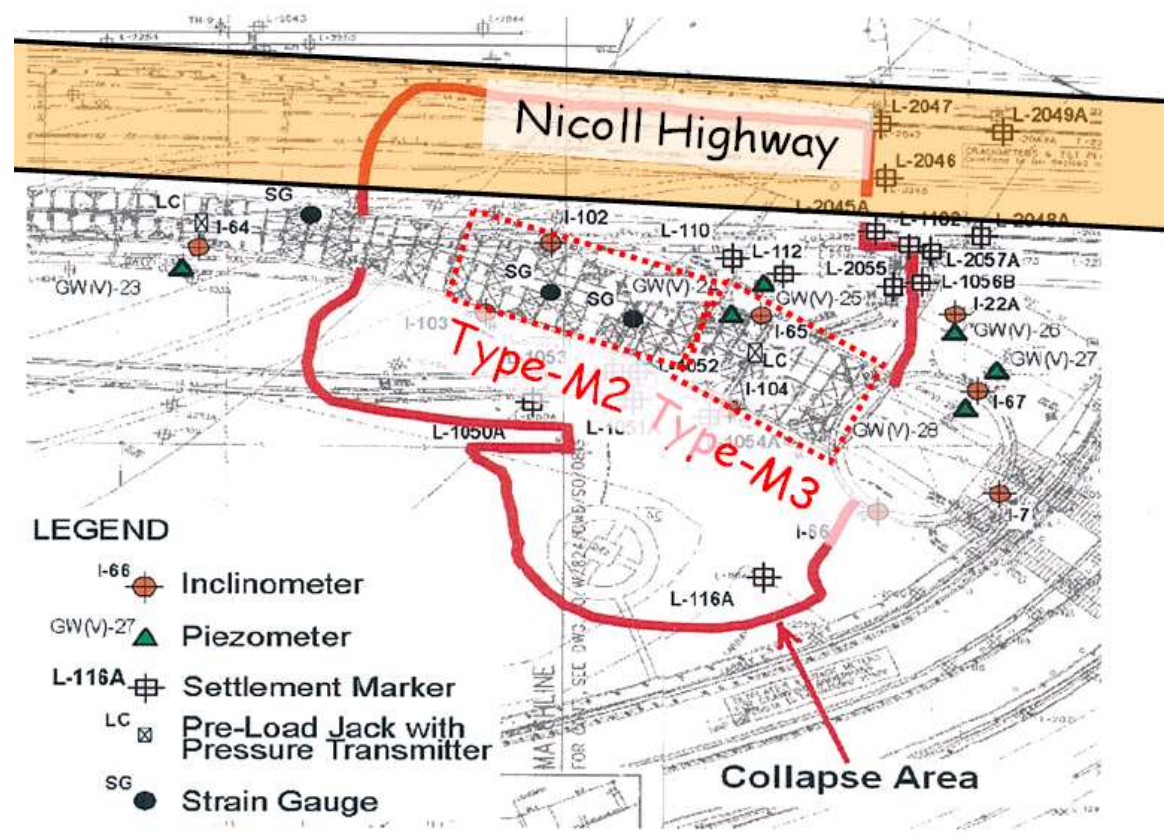




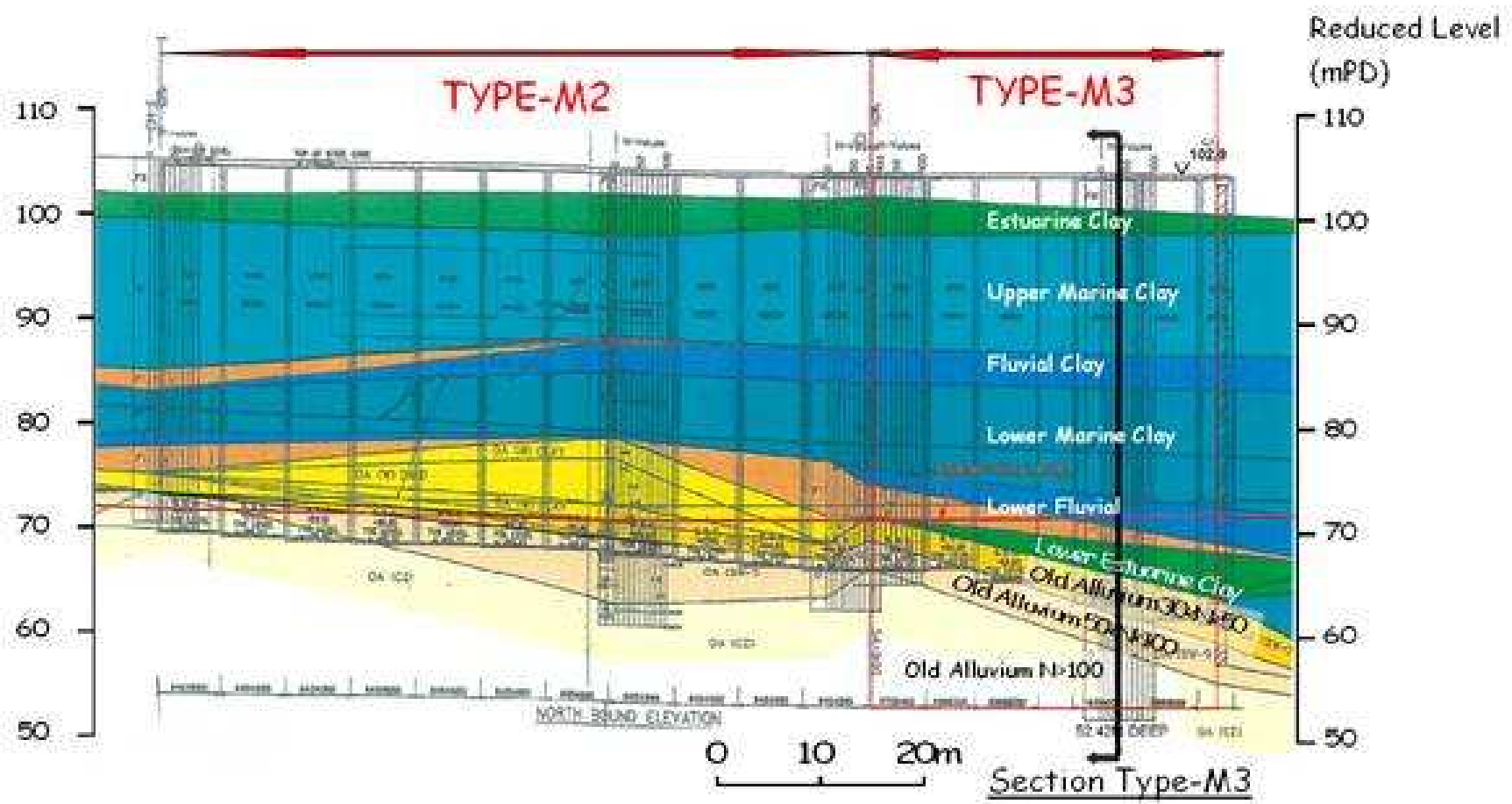

Fig.2 Geotechnical Section used for design phase

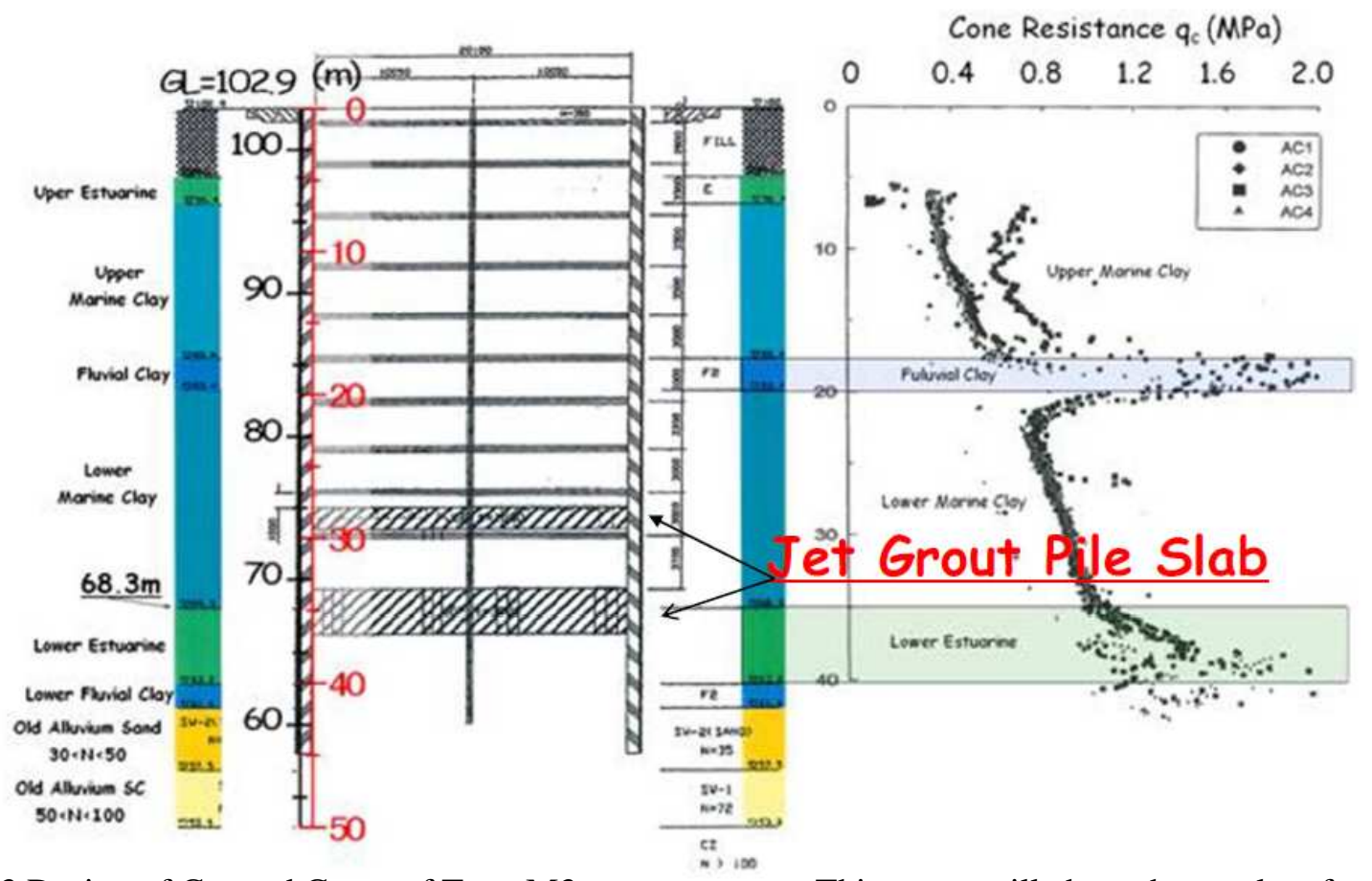

Fig.3 Design of Cut and Cover of Type M3

COI reported their conclusion on 13 May 2005 to the Minister of Manpower, Government of Singapore, who also released the report to the public(COI report, 2005).

The COI report concludes the accident was associated with two inadequate designs of "effective method of analysis for cut and cover excavation" and "wailer system."
This paper will show the results of monitoring and how the process to the failure could be traced.

\section{CUT AND COVER SECTION OF M3 ZONE}

As shown in Fig.1, the section is parallel to the existing Nicoll Highway on the ground surface and consists of different types of retaining wall including M2 and M3 that failed as shown in Fig.1.

As shown in Fig.3, the special design was two sets of Grout slabs that had been installed before the 
excavation started. The depth of the excavation was planned to GL-34.5

$\mathrm{m}$ above the lower grout slab.

The cone penetration resistance shown in Fig.3 shows very soft soil down to $35 \mathrm{~m}$ from the surface where stiff clayey soil continues.

\section{INSTRUMENTATION}

The site was rather well instrumented to monitor settlement, pore water pressure, strut strain, as well as inclination along diaphragm wall as shown in Fig.4. Settlement was to monitor the ground where Nicoll Highway passes north of the excavation site nearby. Decrease of pore water pressure that would cause consolidation settlement of the foundation of the Nicoll Highway was also monitored.

Inclinometer monitoring points at I-65 and I-104 were installed along the diaphragm wall where the electric cable of $66 \mathrm{kVolt}$ had been installed and the diaphragm walls were missing at the sections where the cable cross over the wall lines.

\section{INCLINOMETER}

The inclinometer guide pipes were installed at I-65 and I-104 at the failed section.
Excavation started on 26 September, 2003, at the M3 Section. The monitored wall deflections from the six strut installation until before the failure took place are shown in Fig.5 as well as chronological time change of excavation with strut and the maximum deflection for I-65 and I-104 in Fig.6.

The allowable deflection could be estimated by mechanical properties of such related materials as diaphragm wall, soils to be excavated, and jet grout pile.

When the excavation starts, the soil inside the excavated zone are under the increase of horizontal stressed with vertical stress decreased. Due to the stress change caused by excavation, the soil ground becomes horizontally stressed with some critical failure strains.

The width of the excavation was $19.85 \mathrm{~m}$.

Table-1 Horizontal strain in soil and JGP

$\begin{array}{cc}\text { total deflection }(\mathrm{cm}) & \text { horizontal strain(\%) } \\ 5 & 0.25 \\ 10 & 0.50 \\ 20 & 1.00 \\ 30 & 1.49 \\ 40 & 1.99\end{array}$

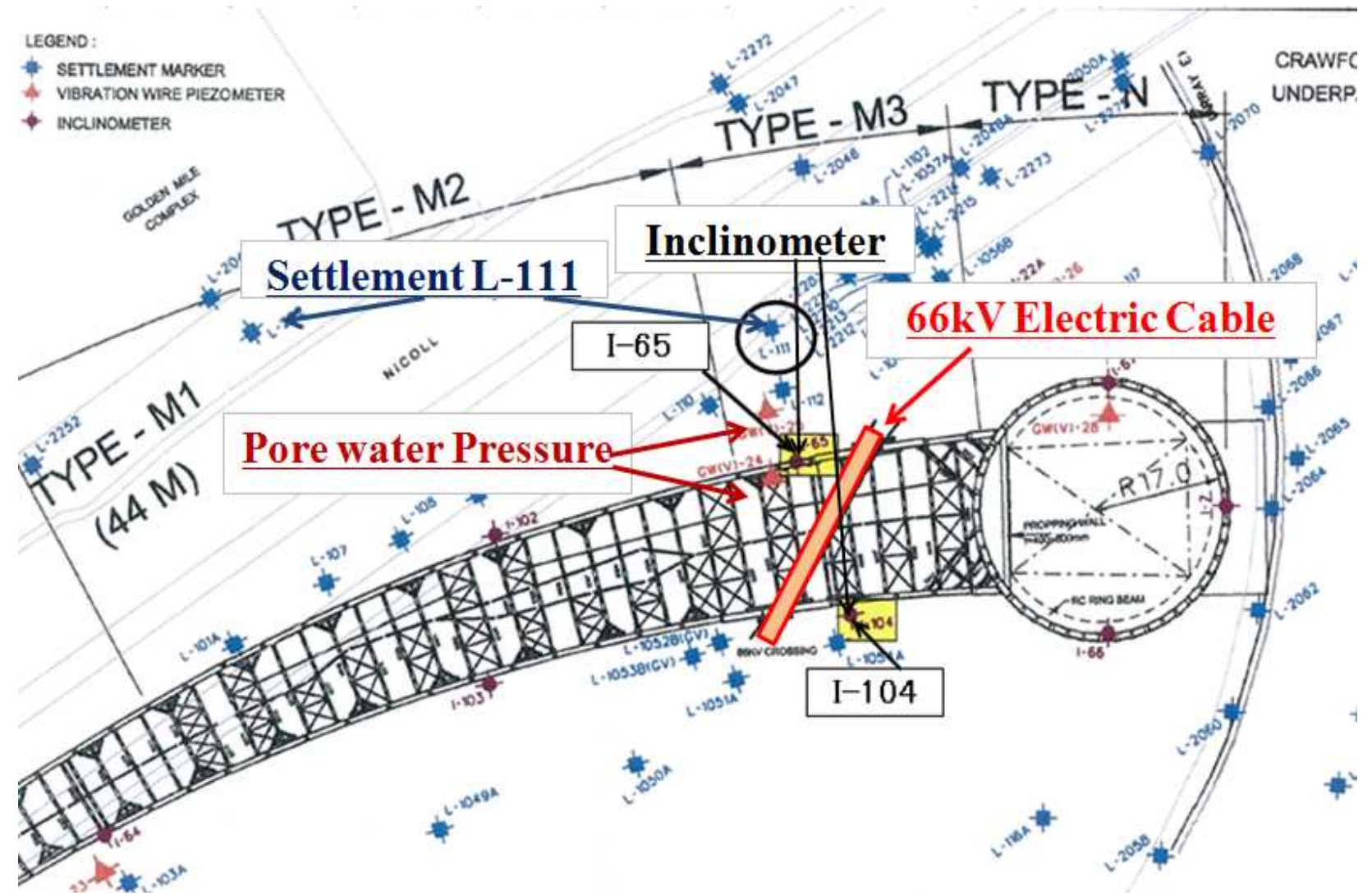

Fig.4 Instrumentation at the failed site 


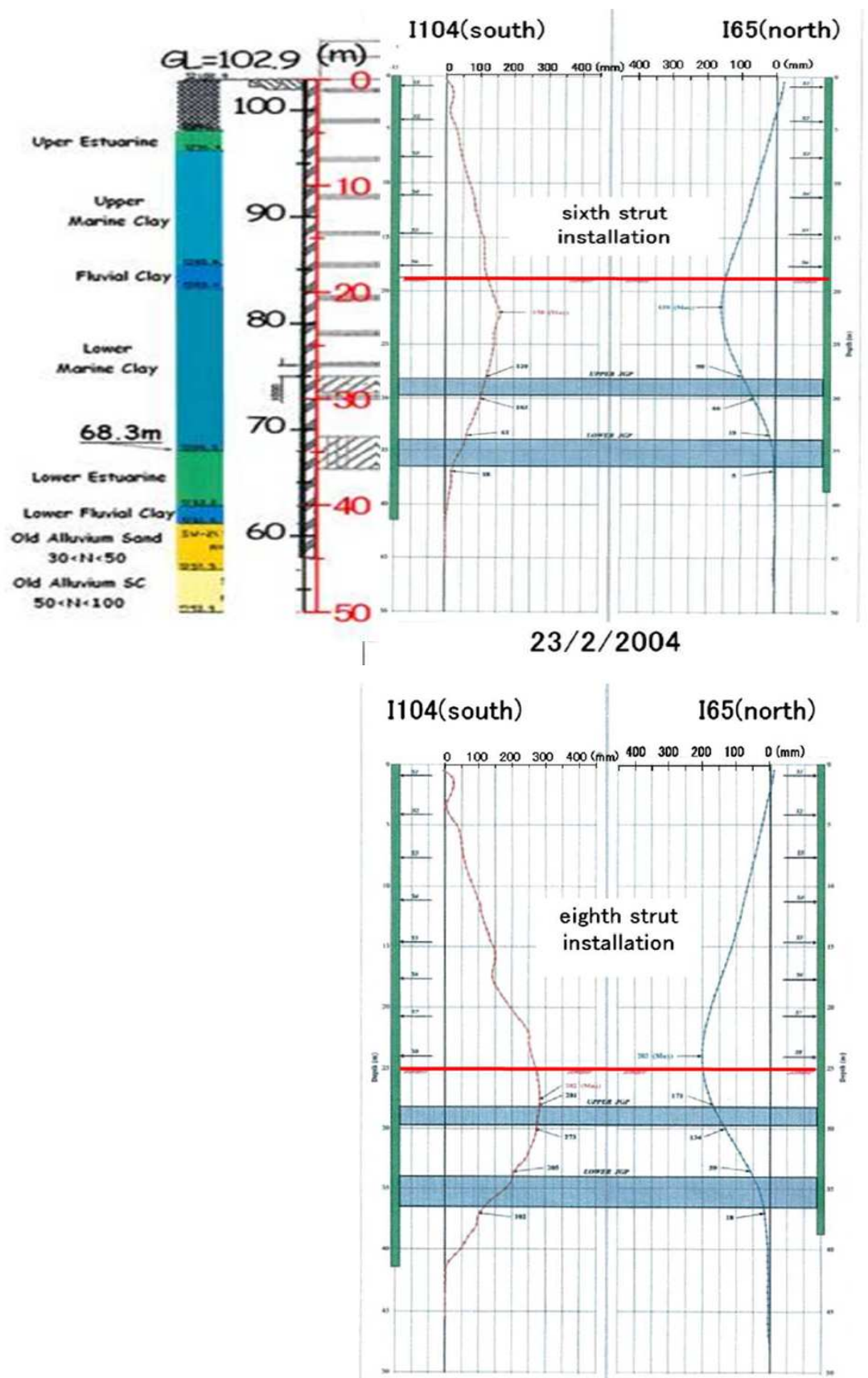

$26 / 3 / 2004$

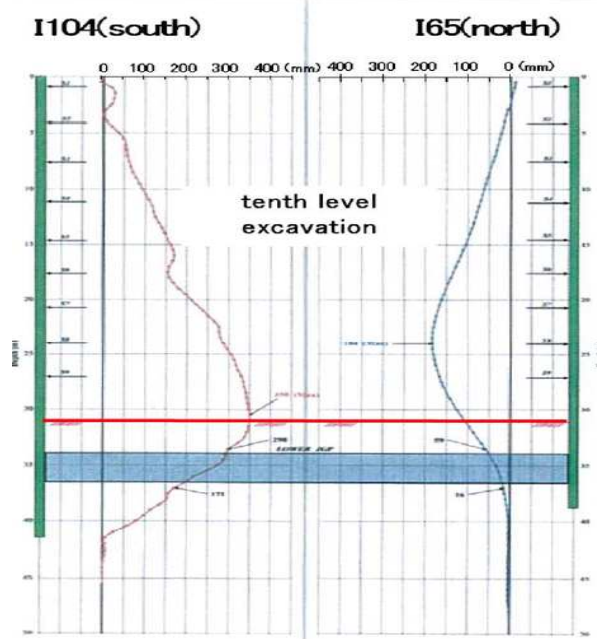

Fig.5 Deflection of diaphragm wall

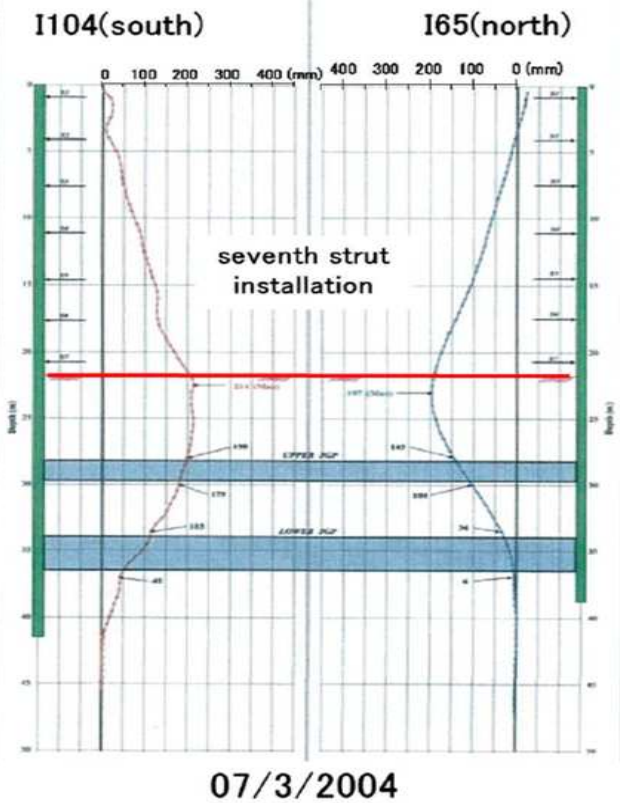

[104(south)

I65(north)

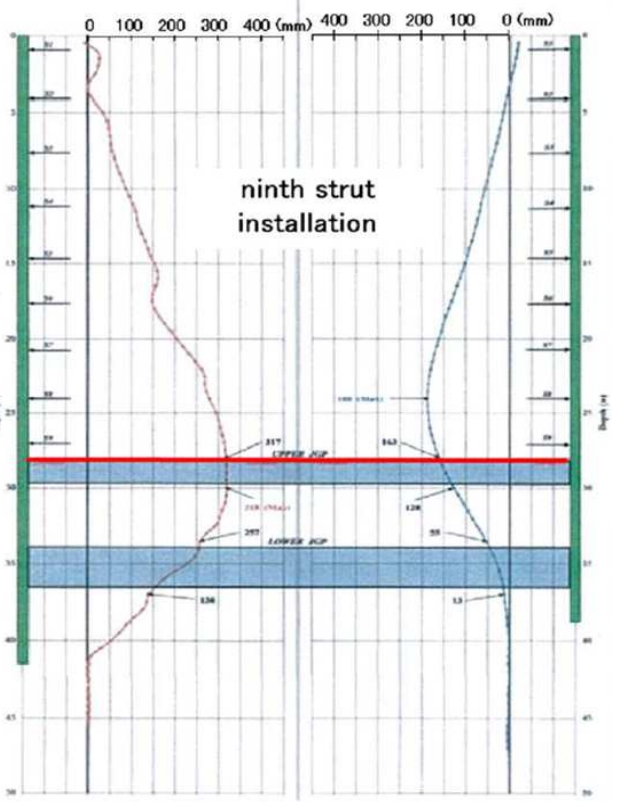

$6 / 4 / 2004$

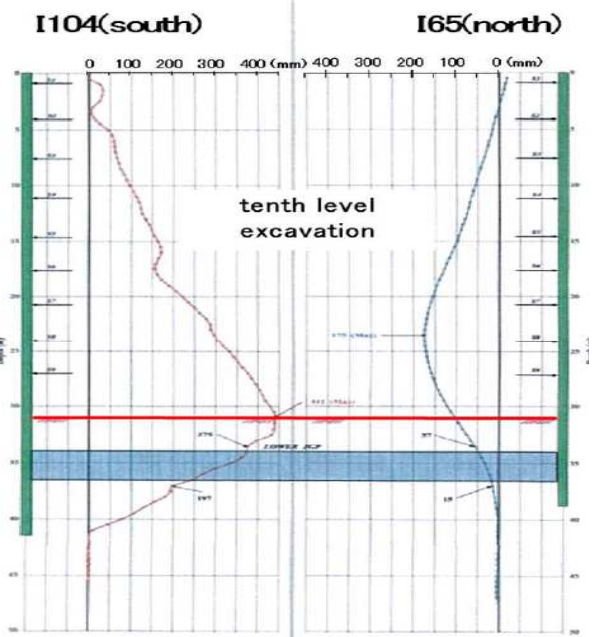

$20 / 4 / 2004$ 

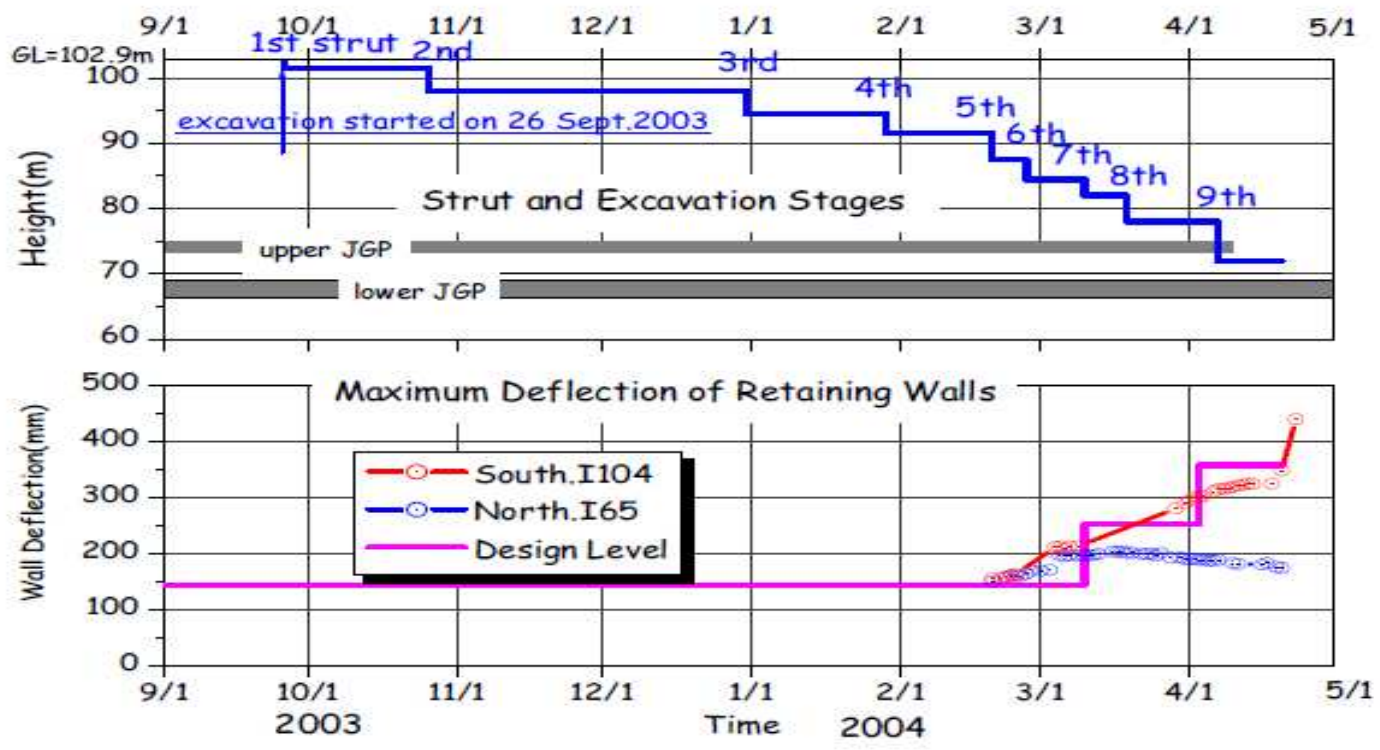

Fig.6 Change of Max. deflections with time

As shown in Fig.5 and Fig.6, the deflection after the sixth strut installation, the total deflection had reached $35 \mathrm{~cm}$, which resulted in about $1.7 \%$.

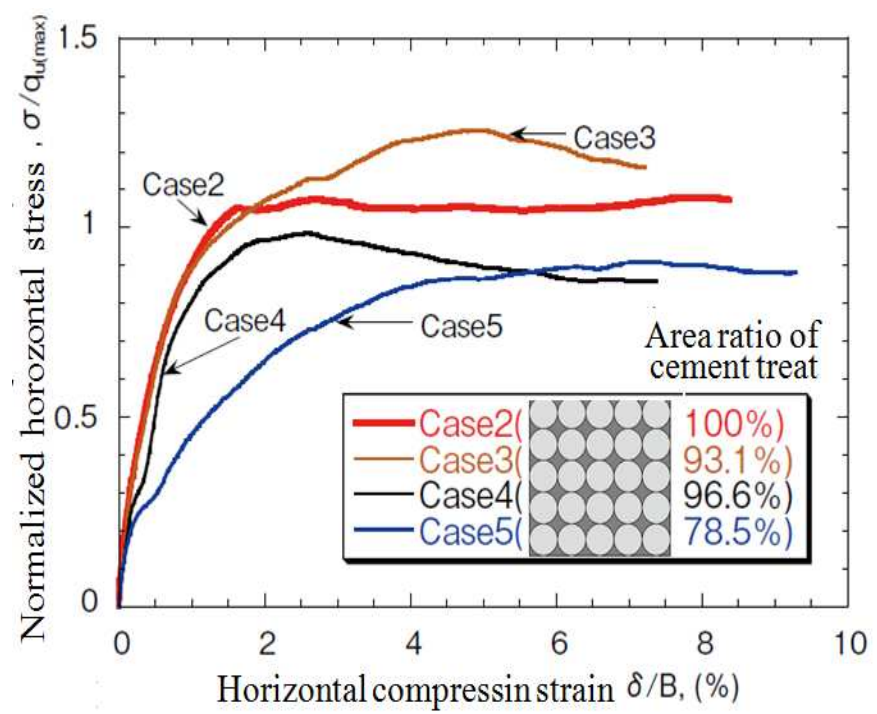

Fig.7 Stress-strain for JGP (Imamura et al.(2008))

Fig.7 shows basic stress and strain for horizontally loaded JGP obtained by laboratory tests (Imamura et al., 2008). The vertical stress was normalized by dividing horizontal stress by the unconfined compression strength of column of JGP $(500 \mathrm{kPa})$.

Fig.7 shows the maximum allowable horizontal strain is estimated as $2 \%$.

If safety margin is given as $\mathrm{FS}=2$, the allowable deflection at the level of JGP is $1 \%$, which is $20 \mathrm{~cm}$ in total, or, $10 \mathrm{~cm}$ for each side.

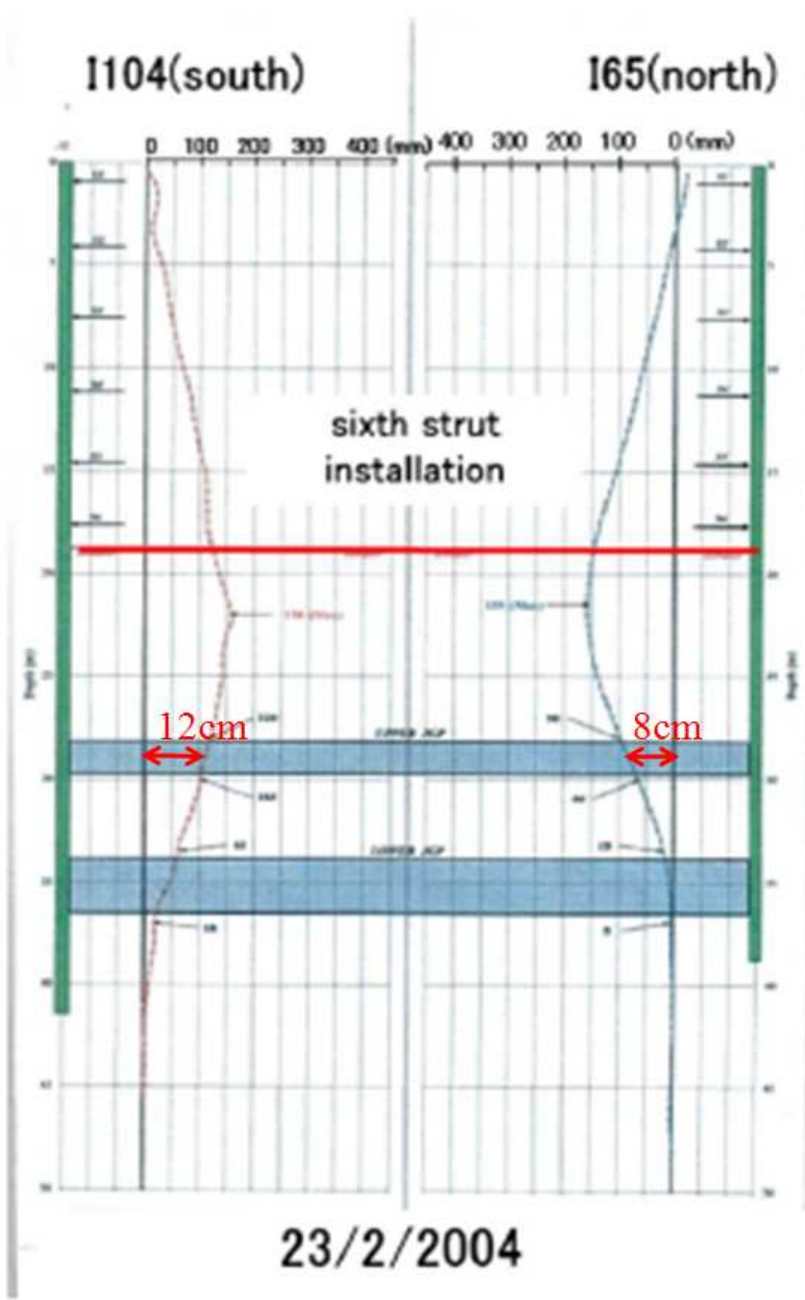

Fig.8 Wall deflection monitored after the sixth strut

As shown in Fig.8, the deflection at the level the upper JGP slab had reached $12 \mathrm{~cm}$ for southern and $8 \mathrm{~cm}$ for the northern side wall. 


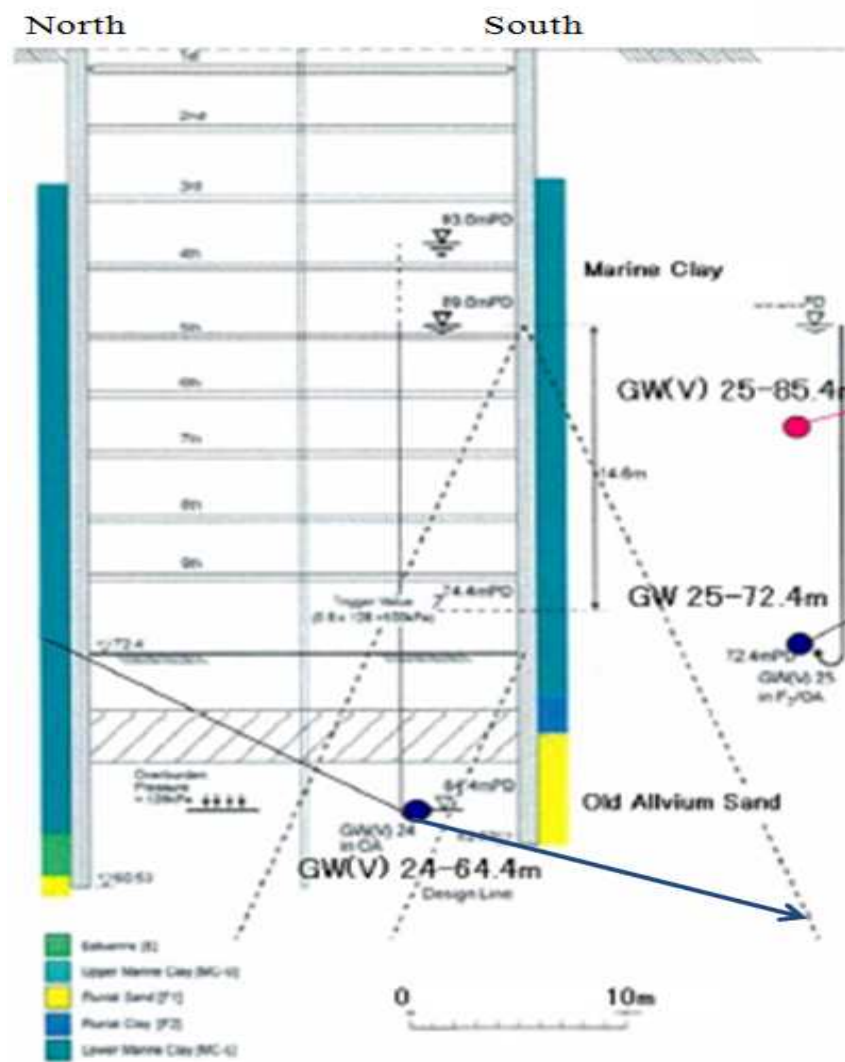

Fig.9 Porewater Monitoring

GW(V) $25-85.4 m$

GWV) $25-72.4 m$

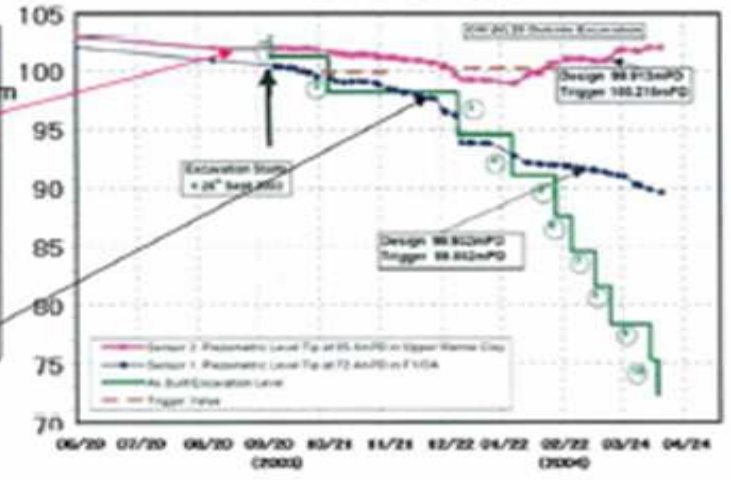

GW(V)- $2464.4 \mathrm{~m}$

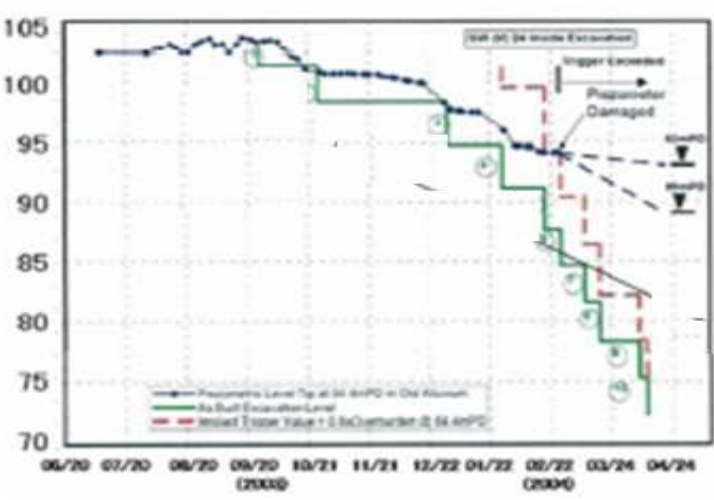

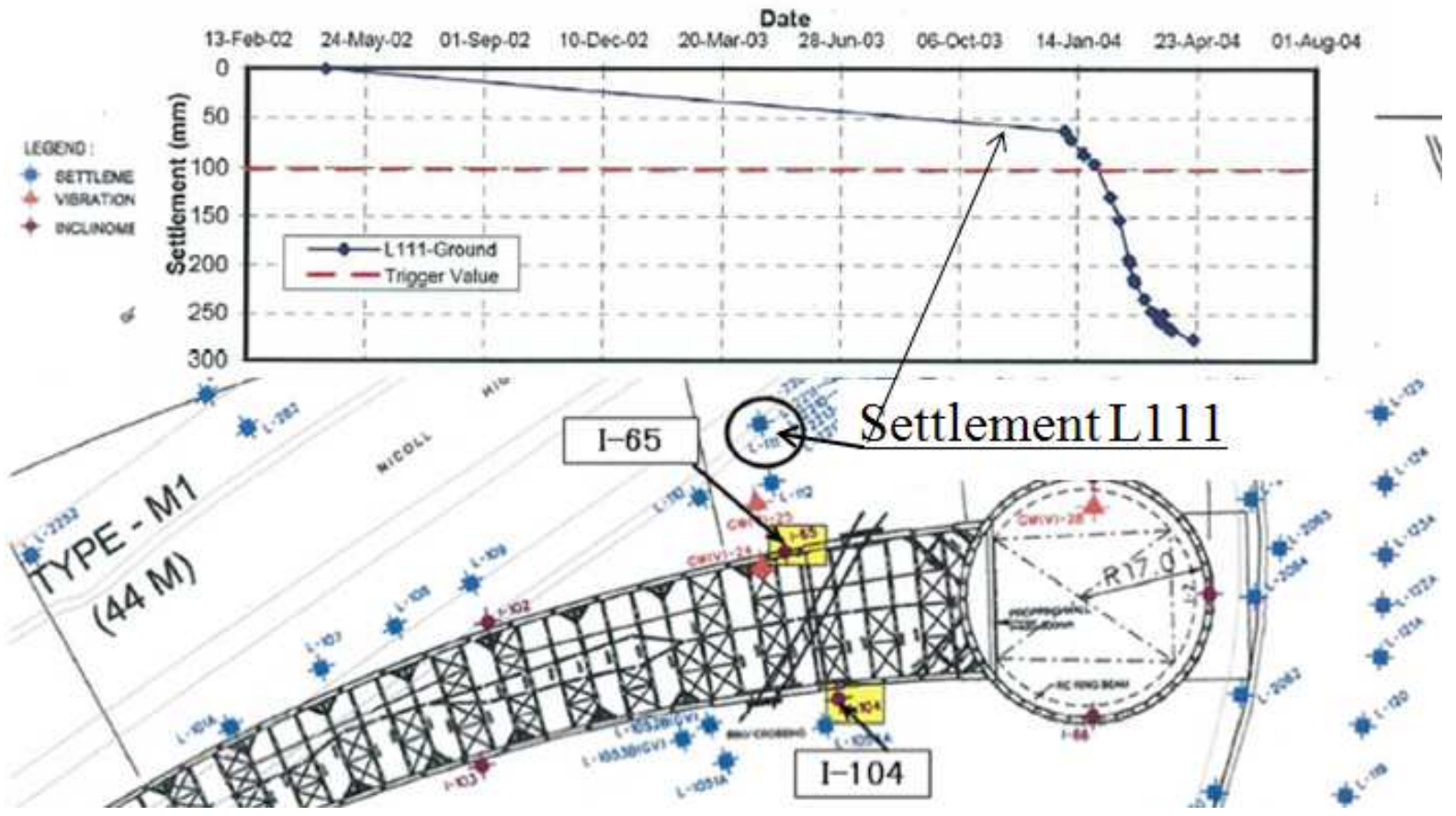

Fig.10 Settlement Gage at L111 and monitored result 
If OM should be applied, this could be the one of the critical phase when some countermeasures should be considered. The possible countermeasures include additional soil improvement in the zone above the upper JGP slab and/or additional strut installation to strengthen the temporary retaining structure.

At this stage, different response of the wall deflections for north and south sides should have been noticed. The lower JGP was observed to have moved into center with about $5 \mathrm{~cm}$ for southern side but no displacement for northern side.

When the strut 8 was completed, the displacement for southern wall had increased to $35 \mathrm{~cm}(25 \mathrm{~cm}$ for southern and $10 \mathrm{~cm}$ for the northern wall) at the upper JGP slab, which was $1.8 \%$ almost in failure.

The asymmetry of the wall deflection for north and south sides was increased with the excavation steps.

When the excavation reached at the upper JGP, the asymmetry became clear and the reason to have caused the phenomena might well be studied. The reason could be any difference of water pressure or earth pressure against for north and south walls.

Many settlement points were installed along the retaining wall adjacent to Nicoll Highway.

\section{SETTLEMENT AND PORE PRESSURE}

The Nicoll Highway is the nearby structure that should not be affected.

monitoring had been installed for the evaluation. Pore water measurements had been also installed near the retaining wall as shown in Fig.9. One of the typical settlement installed at L111 was shown in Fig.10. The level of the ground surface was $\mathrm{GL}=+102.9 \mathrm{~m}$ RL.

Fig.11 shows a comparison between the max deflection at I-65 and settlement at L-111 with the same time scale.

The pore water pressure was monitored at two depths at GL-17.5m and $-30.5 \mathrm{~m}$ of behind the diaphragm wall. The ground water was observed GL$2 \mathrm{~m}$ in general in the area.

The ground settlement at L111 was gradually had taken place and reached about $10 \mathrm{~cm}$ in January 2004. After this point, the settlement had increased rather rapidly with time.

The porepressure at GL-17.5m had gradually decreased with excavation stage.

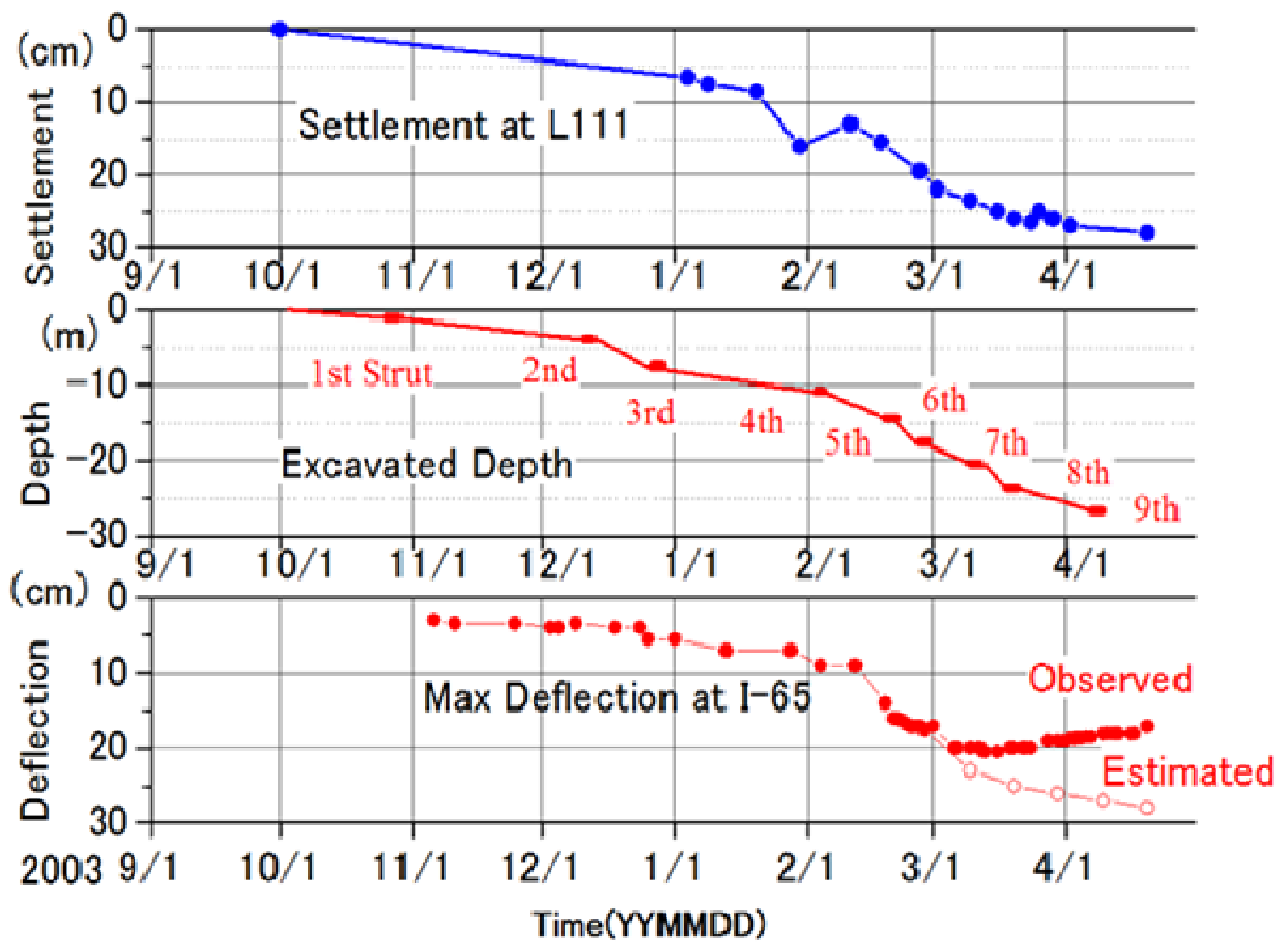

Fig.11 Settlement vs. Deflection 


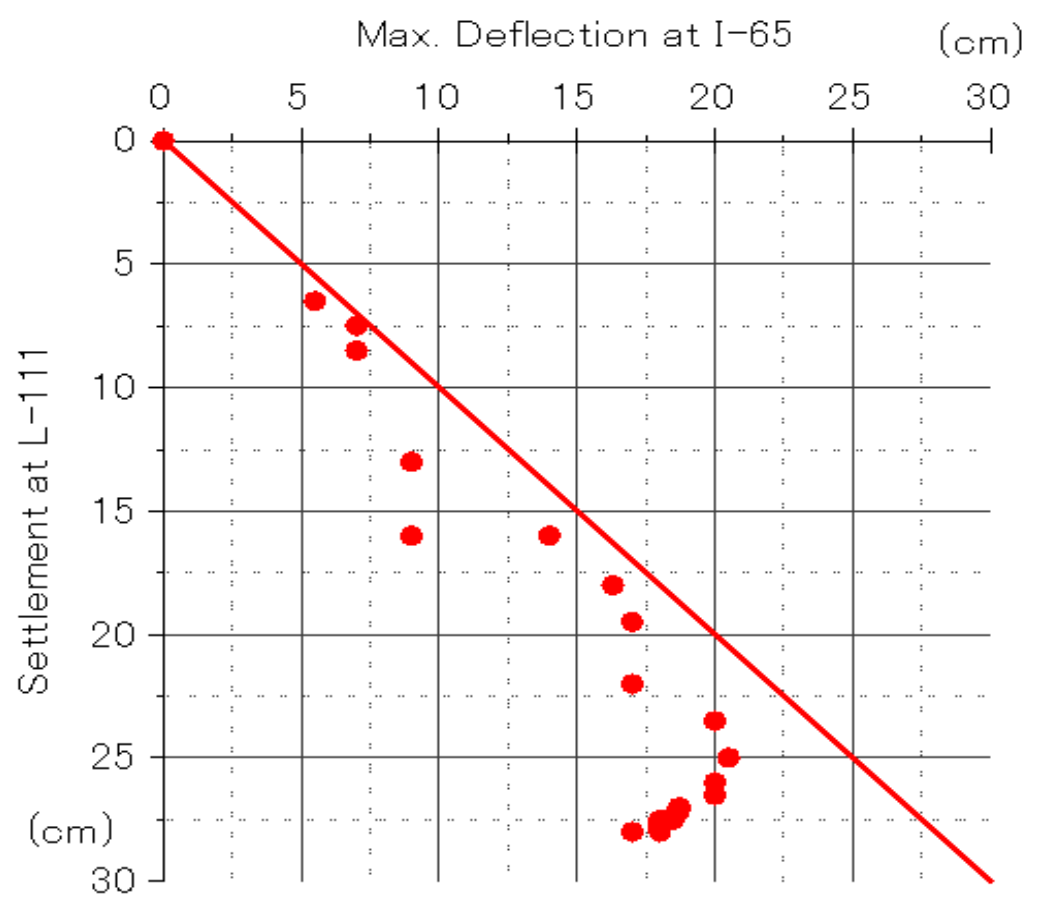

Fig.12 Max. Deflection at I-65 vs. Settlement at L111

The decrease of the pore water pressure might be caused by inwards movement of the diaphragm wall that had resulted in volume expansion of the soil behind the wall.

The settlement at L111 was caused either by consolidation or displacement of diaphragm wall.

Since the settlement was increased so fast, the settlement was very likely considered by the movement of diaphragm movement.

\section{SETTLEMENT AND MAX DEFLECTION}

The max deflection at I-65 that is shown in Fig.6 shows its max deflection at the excavation stage after the sixth strut installation. After this point, the maximum deflection was decreased, which implies the diagram wall of the north side was moving backwards.

Fig.12 shows the relationship between the settlement and the maximum deflection. Until March 1, 2004, the settlement at L-111 is almost the same amount of the max. deflection at I-65. The direct relation of the settlement of the surface ground with the max. deflection means that the settlement is not caused by consolidation but the compensation of the soil volume caused by the retaining wall. After March 1, the settlement was continued to increase. On the other hand, the deflection had stopped and even gone backwards movement.
The backwards movement of the diaphragm wall is not easy to understand. This might be caused by the displacement assumption for the inclination calculation. It is a common practice to assume the bottom point of the inclinometer guide pipe that is embedded within rather dense sand or hard clayey layer is assumed as a fixed point. It is rather realistic to consider the bottom of the inclination guide pipe had moved. Fig.11 shows the estimated increase of the deflection assuming the linear relationship between the settlements at L-111 and the max deflection at I-65 as in Fig.12, which resulted in about $28 \mathrm{~cm}$.

\section{LESSONS LEARNT}

The author had selected several topics from the failure of excavation in Singapore that happened on 20 April 2004 from the view points of OM as well as instrumentation, which was not referred in the report of Committee of Investigation.

\subsection{General Review of Applicability of Observational Method in the Failure}

Among many monitoring items, displacement is much clear than stress or force. If the failure strains are known before the construction starts, displacement criteria to avoid failure of different materials might well be established. In the case under discussion, allowable horizontal displacement for jet grout pile slab was discussed. 


\subsection{Necessity of specialized OM Engineer for geoconstruction}

If OM should be applied to a any geotechnical construction, it is not easy to implement the process without a good quality of geo-engineer who is basically geotechnical engineer and yet has a profound knowledge on the instrumentation. The author believes that independent professional field of "OM and Instrumentation in $\mathrm{Ge}$ otechnical Engineering" must be separated from the common geotechnical engineering and authorizing system should be established to select and to give the status. It is also necessary legal enforcement to include the engineer who hold the status of OM and Instrumentation in Geotechnical Engineering.

\subsection{Measurement of Displacement of Top of Guide Pipes for Inclinometer Measurement}

In most geotechnical construction sites, the inclinations are measured using guide pipes and reference point is selected at the bottom of the pipe.

However, in an excavation site, excavation depth approached to final level, the overburden pressure decreases and becomes much easier for bottom of the guide pipe to be displaced than you might consider.

To avoid any misguided result, the displacement of the top of the guide pipe should always be monitored when the inclinometers are measured.

.GPS is a good system for automatic monitoring instead of manual survey when the OM should be applied in rather long period.

\subsection{Interpretation of Geotechnical Behavior based upon related Monitored Data}

It is important to discuss settlement data with deflection of the nearby retaining wall. The relationship among various monitored items provides important and vital information to understand the site conditions.

\subsection{Effective or/and Total Stress?}

The traditional soil mechanics assumes and discuss failure in terms of stress. Since the characteristics of soil changes with various factors and conditions, some simplification was necessary to obtain some conclusion.

One of the unique condition to be considered in soil mechanics is "drained" or "undrained."

When stress path that is expected for construction process is known, the soil specimen may be tested to along the stress path to obtain strength parameters for "Total Stress" approach.

When pore pressure is monitored during the test, "Effective Stress" approach may also be available. Additional information of the pore pressure that is generated during the shearing process due to dilatancy is vital for the Effective Stress approach.

Discussion of total or effective stress is for only design stage. In the design stage, various conditions are assumed as safer side. When the construction site allows "undrained condition," the total stress approach may still be applied during the construction to discuss the safety in terms of stress level.
Since the deformation parameters of soil generally depend upon such factors of effective confining pressure, stress path, and other several factors, effective stress approach will give much easier to deal with deformation analysis than total stress approach.

\subsection{ISO Standardization for OM in geotechnical engineering}

In early stage of soil mechanics, big projects are not so many and such giants like Terzaghi and Peck could work by themselves. At present, it becomes rather common to implement huge geotechnical construction. Most failed cases are without monitoring instrumentation or lack of knowledge of how to interpret the monitored data even though instrumented.

We need to create the standard of basic principles of instrumentation and how to implement OM in geotechnical construction as one of ISO in geotechnical engineering.

It is necessary to have 5 member countries of ISO to make such a new item.

\section{CONCLUSION}

The failure of the failed excavation work in Singapore 20 April 2004 is reviewed in terms of instrumentation and OM.

Conclusions are obtained as follows,

1. Observational Method provides the basic approach to complete geotechnical construction with safety.

2. It is necessary to provide a special geotechnical engineer who understands not only geotechnical engineering but also instrumentation and observational method.

3. It is also pointed out such key information of displacement of top of guide pipe for inclinometer should be prepared.

4. ISO standardization for OM is highly recommended.

5. Effective and Total stress approach should be discussed for not only obtaining safety of the project as well as deformation.

\section{REFERENCES}

The Committee of Inquiry (2005)Report of Committee of Inquiry into the incident at the MRT circle line worksite that led to the collapse of Nicoll highway on 20 April, 2004, Ministry of Manpower, Gov. of Singapore

S.Imamura et al.(2008)"Lateral Deformation Characteristics of Footing Beam improved," Technical Report, Nishimatsu Corp., Vol.31, pp7-12 by DMM in Earth-Retaning Support 